\title{
THE WAVE RUN-UP SIMULATOR, THEORY AND FIRST PILOT TEST
}

\author{
Jentsje van der Meer ${ }^{1}$, Yvo Provoost ${ }^{2}$ and Gosse Jan Steendam ${ }^{3}$
}

\begin{abstract}
The idea of the Wave Run-up Simulator is based on the experiences with the Wave Overtopping Simulator. It is possible to simulate wave tongues overtopping a dike crest in reality. It must also be possible to simulate waves in the run-up and run-down zone of the seaward slope. This is the zone after waves have broken and when they rush-up the slope. The present paper describes this new idea of the Wave Run-up Simulator, why it is useful to develop the machine, to perform research with it and to develop a prediction method for slope strength. In fact, a prediction method can already be developed from the Cumulative Overload Method, which was developed on the basis of results with the Wave Overtopping Simulator, see Van der Meer et al. (2010). It also means that tests on the seaward slope will be done for validation purposes only. The paper describes in detail what is known about the movement of waves in this run-up zone and what actually the Wave Run-up Simulator has to simulate. Not a lot of research has been performed to describe the wave run-up process in detail, physically nor statistically. Finally, the pilot test has been described including hydraulic measurements on the slope.
\end{abstract}

Keywords: overtopping; run-up; simulator; flow velocity

\section{STARTING FROM WAVE OVERTOPPING SIMULATION}

The idea to develop a Wave Run-up Simulator is of course based on the experience with the Wave Overtopping Simulator, Van der Meer et al. (2006, 2007, 2008, 2009, 2010), Akkerman et al. (2007), Steendam et al. (2008, 2010, 2011) and Hoffmans et al. (2008), including development of Overtopping Simulators in Vietnam (Le Hai Trung et al. (2010)) and in the USA (Van der Meer et al. (2011) and Thornton et al. (2011)). After five years of extensive testing and very recently the development of a prediction method (Van der Meer et al. (2010)), further testing with the Wave Over-topping Simulator will be focused on validation of the prediction method and testing of river dikes and possibly regional dikes, which have quite different features than sea and lake dikes. The objective of the Wave Overtopping Simulator is to simulate the hydraulic behaviour of wave overtopping on real dikes and to observe the damage development of grassed slopes, leading to a prediction method for strength of dikes due to wave overtopping. The main reason for this in situ testing is that grass and clay cannot be scaled and tested in a small scale hydraulic facility.

The Wave Overtopping Simulator simulates overtopping wave tongues on crest and landward slope of dikes. Waves that reach the crest in real situations are simulated, not the wave breaking and wave run-up or run-down on the seaward side. The idea of the Wave Run-up Simulator is to simulate the wave run-up and run-down on the seaward side, but above the zone of breaking waves. Many sea and lake dikes exist in the Netherlands, where the impact zone of waves is protected by block revetments or asphalt, but the most upper part of the seaward side consists of grass only. It means also that only the upper part of the largest run-up events have to be simulated.

During wave run-up the water runs up a slope and then, if there is no or hardly overtopping, will run-down till the next up-rushing wave arrives. With wave overtopping there is a relationship between overtopping wave volume and flow velocity and flow depth. This is not the case for wave run-up, where flow velocities and flow depths are the direct in-put for simulation, and of course the required run-up level.

The main similarity, however, is that the cumulative overload method (Van der Meer et al. (2010) is based on flow velocities and quality of the grass cover. A good description of the velocities in the run-up and run-down zone gives an initial prediction method for the strength of this zone. This is in contrast with the development of the Wave Overtopping Simulator, where first years of testing was based on gathering knowledge and then developing a prediction method.

A prediction method for strength of grass covers in the run-up and run-down zone can already be developed. The objective of the Wave Run-up Simulator is then to validate this method in real situations. The copy right of the idea of the Wave Run-up Simulator is based on the submission of a research topic to the ENW research agenda on 13 December 2010.

\footnotetext{
${ }^{1}$ Van der Meer Consulting BV, P.O. Box 423, 8440 AK, Heerenveen, the Netherlands, jm@vandermeerconsulting.nl

${ }_{3}^{2}$ Rijkswaterstaat Projectbureau Zeeweringen, the Netherlands, yvo.provoost@rws.nl

${ }^{3}$ Infram, the Netherlands, gosse.jan.steendam@infram.nl
} 
The Wave Overtopping Simulator has been designed and constructed in 2006 and has been used since then for destructive tests on dike crest and landward slopes of dikes or levees under loading of overtopping waves. The setup of the Overtopping Simulator on a dike or levee is given in Figure 1, where the Simulator itself has been placed on the seaward slope and it releases the overtopping wave volume on the crest, which is then guided down the landward side of the dike.

Water is pumped into a box and released now and then through a butterfly valve, simulating an overtopping wave volume. Electrical and hydraulic power packs enable pumping and opening and closing of the valve. A measuring cabin has been placed close to the test section.

Released volumes in a certain time are according to theoretical distributions of overtopping wave volumes, depending on assumed wave conditions at the sea side and assumed crest freeboard.

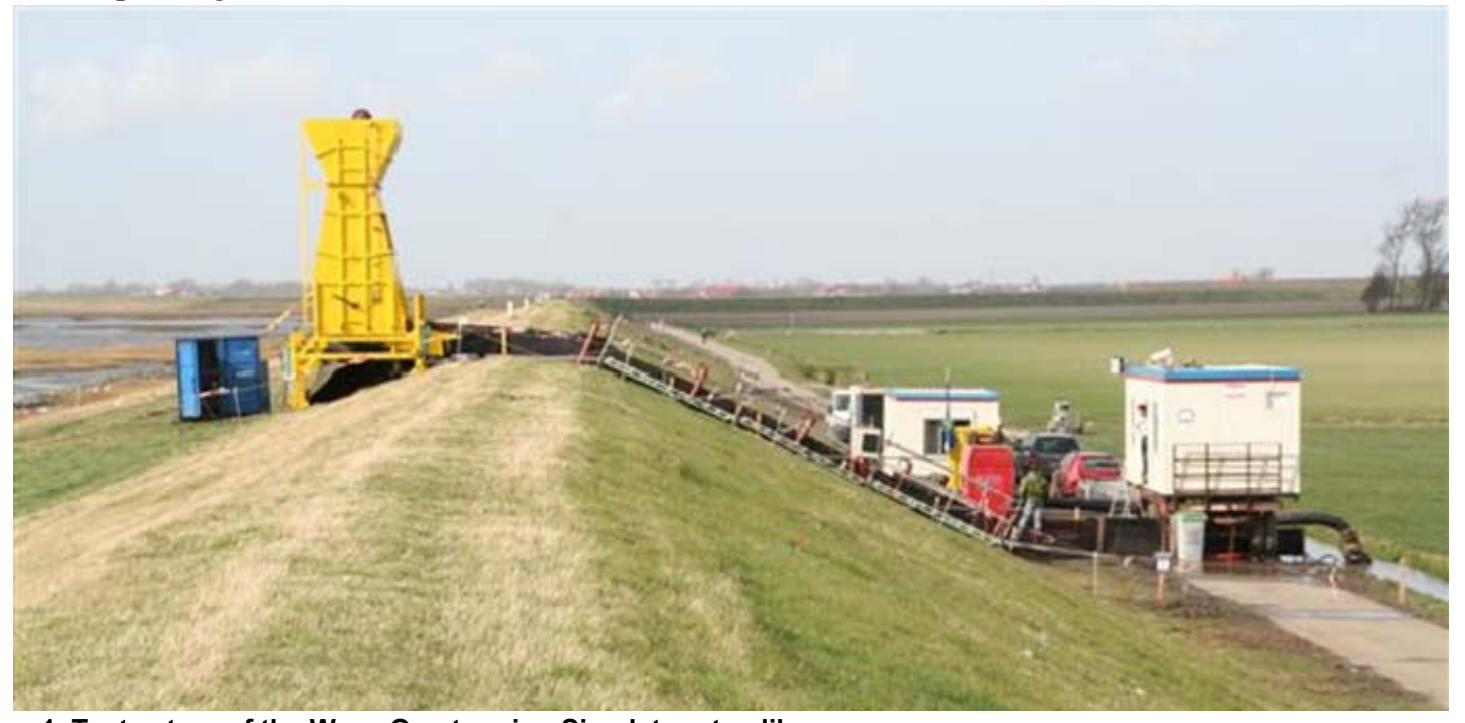

Figure 1. Test set-up of the Wave Overtopping Simulator at a dike.

\section{THE WAVE RUN-UP SIMULATOR}

When incident waves reach a dike or levee, they will break if the slope is fairly gentle. This may cause impacts on the slope in zone 2, see Figure 2. When large waves attack such a dike the seaward side in this area will often be protected by a placed block revetment or asphalt. The reason is simple: grass covers cannot withstand large wave impacts, unless the slope is very mild.

Above the impact zone the wave runs up the slope and then rushes down the slope till it meets the next up-rushing wave. This is the run-up and run-down zone on the seaward slope (zone 3 in Figure 2). Up-rushing waves that reach the crest will overtop the structure and the flow is only to one side: down the landward slope. Zone's 4 and 5 can be tested with the Wave Overtopping Simulator, as described in the previous section.

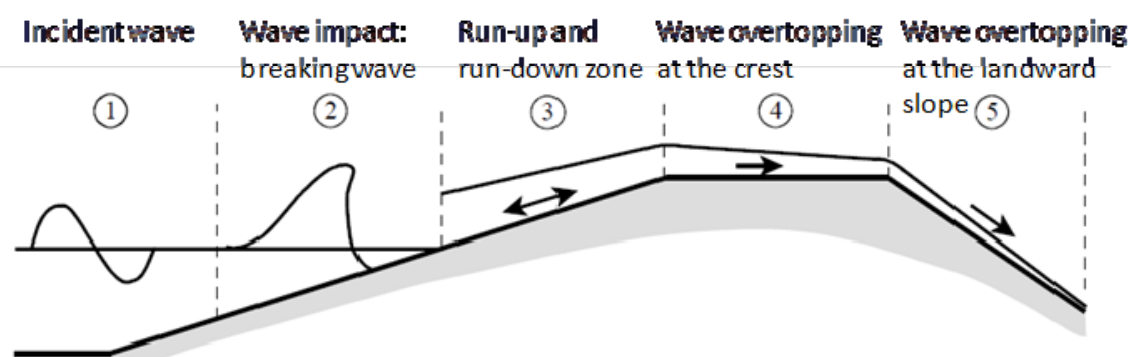

Figure 2. Process of wave breaking, run-up and overtopping at a dike (figure partly from Schüttrumpf, (2001).

The seaside of a grassed dike cannot be tested with the Wave Overtopping Simulator. Overtopping water is released from the Simulator and flows over the crest and down the landward slope. The flow of water is only down the landward slope and does not return to the Simulator. But this is the case at the seaward side in the run-up and run-down zone. The objective of a Wave Run-up Simulator would be to test strength of grass slopes in the run-up and run-down zone at the seaward side.

The first question to answer is, do we need such a Run-up Simulator? It is clear that wave overtopping may give erosion to the landward side of any dike, whether it is a sea or lake dike with 
fairly severe wave attack or a river dike with relatively small overtopping waves. This situation is different when we consider a grassed seaward slope in the run-up and run-down zone.

When the wave attack is quite small, like for river dikes, the seaward side is often not protected by an artificial system and the grassed slope should also be able to with-stand wave impacts (zone 2 in Figure 2) of these relatively small waves. Tests in wave flumes have shown that grassed slopes are indeed able to withstand small waves, say less than $1 \mathrm{~m}$. If grassed slopes can withstand small wave impacts, then they are certainly able to withstand the lower forces in the wave run-up and run-down zone. The Wave Run-up Simulator cannot simulate wave impacts. And therefore there is no need for a Wave Run-up Simulator to test the seaward side if the impact zone is also protected by grass.

Many sea and lake dikes have artificial protection in the impact zone of the waves and above this zone, at the run-up and run-down zone, the slope is covered by grass. This upper part of the slope, often above a protected berm, gets only wave run-up and run-down and no wave impacts.

Wave run-up at these upper seaward slopes may give larger velocities than at the crest and landward slope during wave overtopping. And the grass is attacked by two sides, from up-rushing water and then by down-rushing water. The conclusion is that a grassed upper slope on the seaward side will experience larger forces by up and down rushing waves than the crest and landward slope by only down rushing waves.

There are many sea and lake dikes (in the Netherlands) with fairly large wave attack where the upper part of the seaward side has only a grass protection. Figure 3 gives an example (as well as Fig. 1), where the Wave Overtopping Simulator was placed just on the upper part of the seaward slope (to test the crest and landward slope). The left side of the picture shows the placed block revetment and an asphalt cycle path, which is part of the almost horizontal berm. The rest of this berm and also the upper slope have grass on clay and are subject to up and down rushing waves.

For the time being, the idea of a Wave Run-up Simulator is more or less similar to the Wave Overtopping Simulator. Differences are that not the volume of the released wave is important, but more the correct velocity at the right location, the simulation of the correct run-up levels and that an up-rushing wave comes (partly) back to the Simulator.

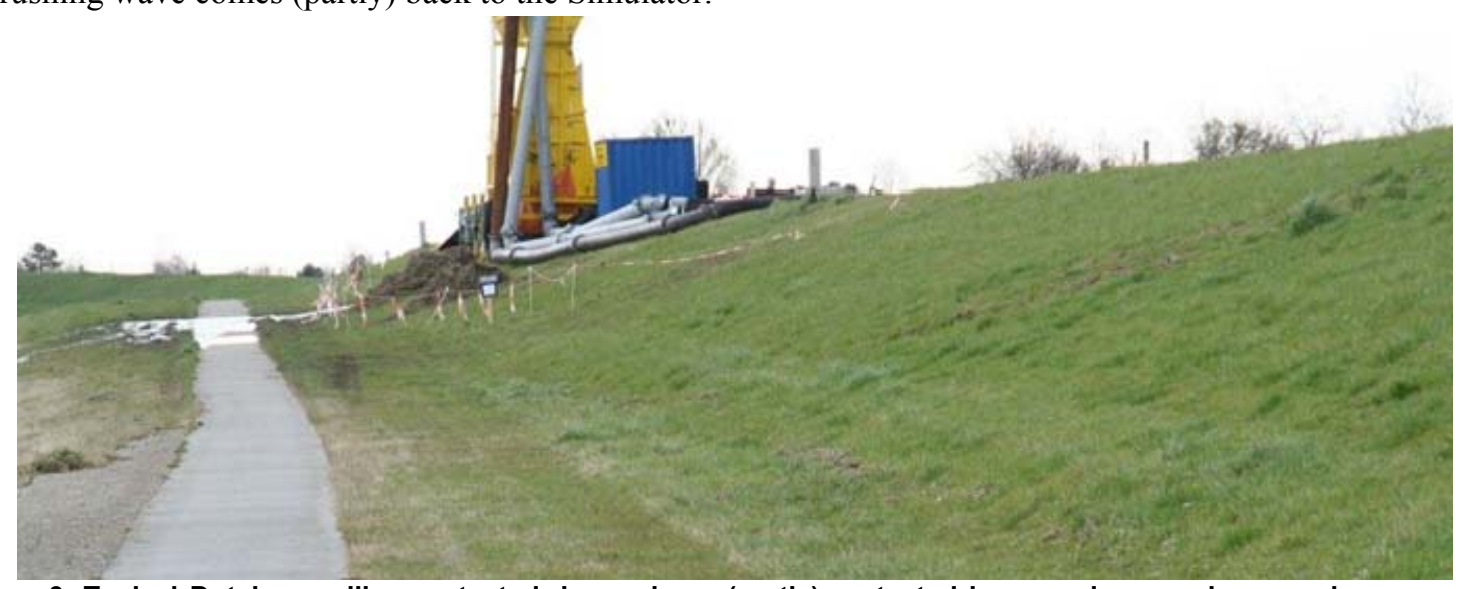

Figure 3. Typical Dutch sea dike: protected down slope, (partly) protected berm and grassed upper slope. This upper slope can be attacked by up-rushing waves.

\section{DESCRIPTION OF THE WAVE RUN-UP PROCESS}

\section{Wave run-up levels}

The engineering design parameter for wave overtopping is the average overtopping discharge, where for wave run-up this is the level on the slope that is exceeded by $2 \%$ of the up-rushing waves $\left(\mathrm{Ru}_{2 \%}\right)$. The EurOtop Manual (2007) gives methods to calculate the overtopping discharge as well as the $2 \%$ run-up level for all kinds of wave conditions and for all types of coastal structures. Knowing the $2 \%$ run-up level for a certain condition is the starting point to describe the wave run-up process. Assuming a Rayleigh distribution of the run-up levels and knowing $\mathrm{Ru}_{2 \%}$ gives all the required run-up levels.

Wave run-up velocities and flow thicknesses

In order to simulate the wave run-up process on a slope during a storm one has to describe the whole process, for each wave. The run-up level is a start, but also run-up velocities and flow 
thicknesses are required. From the wave overtopping tests it is known that the front velocity is the governing parameter in initiating damage to a grassed slope. Focus should therefore be on describing this front velocity along the upper slope.

Some researchers have looked at various zones of the wave-structure interaction at a dike, as given in Figure 2. Those researchers with work from the previous century are mentioned in the PhD-thesis of Schüttrumpf (2001). Schüttrumpf performed small scale and large scale tests on wave run-up and wave overtopping and measured and analyzed amongst others velocities and flow thicknesses. His work is a main basis. At the same period Van Gent (2002) performed flume tests on wave overtopping and also measured velocities and flow thicknesses at crest and landward slope. A combined paper was given by Schüttrumpf and Van Gent (2003), summarizing the two investigations. Bosman (2008) tried to explain the differences between the results as described in Schüttrumpf and Van Gent (2003), by introducing a slope angle into the equations. Later work under the EU Hydralab project Flowdike did not validate Bosman's hypothesis and the final conclusion might be that there is quite some uncertainty or scatter in predicting wave run-up velocities or flow thicknesses. A detailed summary of all the work mentioned is given in Van der Meer (2011). Only the final results are given here.

By only considering random waves and the $2 \%$-values, the equations for run-up velocity and flow thickness become:

$$
\begin{gathered}
\mathrm{u}_{2 \%}=\mathrm{c}_{\mathrm{u} 2 \%}\left(\mathrm{~g}\left(\mathrm{Ru}_{2 \%}-\mathrm{z}_{\mathrm{A}}\right)\right)^{0.5} \\
\mathrm{~h}_{2 \%}=\mathrm{c}_{\mathrm{h} 2 \%}\left(\mathrm{Ru}_{2 \%}-\mathrm{z}_{\mathrm{A}}\right)
\end{gathered}
$$

where:

$\mathrm{u}_{2 \%} \quad=$ run-up velocity exceeded by $2 \%$ of the up-rushing waves

$\mathrm{c}_{\mathrm{u} 2 \%}=$ coefficient

$\mathrm{g} \quad=$ acceleration of gravity

$\mathrm{Ru}_{2 \%} \quad=$ maximum level of wave run-up related to the still water level swl

$\mathrm{z}_{\mathrm{A}} \quad=$ location on the seaward slope, in the run-up zone, related to swl

$\mathrm{h}_{2 \%} \quad=$ flow thickness exceeded by $2 \%$ of the up-rushing waves

$\mathrm{c}_{\mathrm{h} 2 \%} \quad=$ coefficient

Table 1 shows a summary of results for $\mathrm{c}_{\mathrm{h} 2 \%}$ and $\mathrm{c}_{\mathrm{u} 2 \%}$, more or less in chronicle order (for more details see Van der Meer (2011)). It seems that both values by Van Gent's work are on the lower side, although his data has minor scatter and the fit with his data is quite good. Four independent other sources give for slopes around 1:3 and 1:4 a value of $c_{h 2 \%}=0.20-0.22$. The large scale 1:6 tests, but also the 1:6 Flowdike 2 tests give a value $\mathrm{c}_{\mathrm{h} 2 \%}=0.29-0.34$. Only the small scale 1:6 slope gives the lower value of $\mathrm{c}_{\mathrm{h} 2 \%}=0.21$, but these tests are probably less accurate as the test duration was only 100 s. There seems to be a difference between the gentle slope of 1:6 and the steeper slopes of 1:3 and 1:4, but there is no real difference between these steeper slopes of 1:3 and 1:4. This makes it difficult to give a relationship with $\cot \alpha$.

A conclusion could be to take $c_{h 2 \%}=0.20$ for slopes of $1: 3$ and $1: 4$ and $c_{h 2 \%}=0.30$ for a slope of 1:6. Consequently, a slope of 1:5 would then by interpolation give $c_{\mathrm{h} 2 \%}=0.25$. This procedure is better

\begin{tabular}{|c|c|c|c|}
\hline Authors & $\begin{array}{l}\text { Seaward slope, } \\
\text { cota }\end{array}$ & $\mathbf{C}_{\mathrm{h} 2 \%}$ & $\mathrm{C}_{\mathrm{u} 2 \%}$ \\
\hline Van Gent (2002) & 4 & 0.15 & 1.3 \\
\hline Van Gent H24 (2002) & 4 & 0.21 & 1.7 \\
\hline Van Gent H1256 (2002) & $3 ; 4 ; 4+$ berm & 0.21 & \\
\hline Schüttrumpf (2001) small scale & 4 & 0.22 & \\
\hline Schüttrumpf (2001) small scale & 6 & 0.21 & \\
\hline Schüttrumpf (2001) large scale TMA & 6 & 0.33 & 1.55 \\
\hline Schüttrumpf (2001) large scale & 6 & 0.34 & 1.39 \\
\hline Schüttrumpf et al. (2002) & 6 & 0.33 & 1.55 \\
\hline Schüttrumpf and Van Gent (2003) & $4 ; 6$ & $0.33 / 0.15$ & $1.37 / 1.3$ \\
\hline EurOtop (2007) & - & $0.055 \cot \alpha$ & 1.55 \\
\hline Bosman (2008) & $4 ; 6$ & $0.10 \cot ^{2} \alpha$ & $0.30 \cot \alpha$ \\
\hline Flowdike 1 - Lorke et al. (2010) & 3 & 0.20 & $0.35 \cot \alpha$ \\
\hline Flowdike 2 - Lorke et al. (2010) & 6 & 0.29 & \\
\hline
\end{tabular}
than to use a formula like $c_{\mathrm{h} 2 \%}=0.055 \cot \alpha$, as given in EurOtop (2007). 
From theory one might expect that $\mathrm{c}_{\mathrm{u} 2 \%}$ should be equal or larger than 1.4. Only Van Gent (2002) shows a little smaller value, but it was noted during analysis that based on his data one may except a little larger value than 1.3. It was also argued that the high value of 1.7 for the $\mathrm{H} 24$ data could be a little lower. Schüttrumpf's large scale data give $\mathrm{c}_{\mathrm{u} 2 \%}$-values of 1.39 and 1.55 . This is well in between the values of Van Gent. In EurOtop (2007) the larger value was chosen. The Flowdike 1 analysis gave $\mathrm{c}_{\mathrm{u} 2 \%}=0.35 \cot \alpha$, leading to values of $1.05 ; 1.4$ and 2.1 for slopes of $1: 3 ; 1: 4$ and $1: 6$. Specially the value for the 1:6 slope is too large.

A conclusion could be to take $c_{u 2 \%}=1.4-1.5$ for slopes between 1:3 and 1:6.

But the main conclusion is that all research that is compared in the present analysis is not always consistent. This may be due to the fact that measurement of velocities and flow depths on structures is not easy, certainly not at a large scale where turbulence and air entrainment may affect the measurements. Or that assumptions, like a linear decrease, are not correct. Moreover, many measurements were performed at the transition between slope and crest, where the wave changes from up-rushing to horizontal. This could also give some extra scatter.

\section{Wave run-up velocities based on analysis of run-up gauge records}

The analysis in the previous section was mainly based on direct measurement of velocity and flow thickness and often at the crest of an overtopped structure and at the landward slope. Direct measurement of velocities has been performed with propellers or electromagnetic velocity meters, sometimes by calculation of front velocities between wave gauges. Analysis was focused on the $2 \%$ exceedance value at the crest.

There is not much research which has been focused on run-up and run-down velocities along the seaward slope. But there is research that measured wave run-up along a non-overtopping slope. The records of these type of measurements show the location of the up-rushing wave front along the slope. The derivative of the change of location gives a front velocity, in the same way as the front velocity can be calculated between two fixed points. The advantage of the wave run-up record is that it shows the front velocity over the full run-up zone. This type of records will be analysed in this chapter. The run-up gauge does not show flow thicknesses and, therefore, the analysis is limited to flow velocity only.

Three data sets were available with the raw data of a wave run-up gauge: Flowdike I on a slope 1:3; Flowdike II on a slope 1:6; and the Petten seadike in the Netherlands: real measurements on the 1:3 upper slope of a seadike.

The Flowdike I and II measurements have a similar set-up, but a different slope. The two slopes of 1:3 and 1:6 cover a large range of slopes applied in reality. Wave overtopping was measured on two different crest levels (with two overtopping tanks for each crest) and wave run-up was measured by a capacitance wire stretched just above a slope, which was high enough to prevent wave overtopping.

At the Petten sea dike a wave run-up gauge has been constructed by means of cells, that detect whether there is water or not. The down slope is 1:4, then a $11 \mathrm{~m}$ long berm of 1:20 at a level of $5 \mathrm{~m}+\mathrm{CD}$ and finally a 1:3 upper slope till a crest height of $12 \mathrm{~m}+\mathrm{CD}$. Measurements were performed during a severe storm on 9 November 2007. The significant wave height close to the dike was about $2.2 \mathrm{~m}$ with a spectral period $\mathrm{T}_{\mathrm{m}-1,0}=10 \mathrm{~s}$ and the water level was about $2.75 \mathrm{~m}+\mathrm{CD}$. This storm condition was more or less constant during 3 hours and 40 minutes, giving 1436 incident waves.

The Flowdike measurements were performed with a set of six wave boundary conditions: three wave heights with for each wave height two wave steepnesses. Such a set was required to get enough data on wave overtopping. For wave run-up the crest height does not play a role and the three wave heights are actually scale tests (a two times smaller wave height should give a two times smaller wave run-up). The two wave steepnesses were $s_{o p}=0.02$ and 0.04 , where $s_{o p}$ is the deep water wave steepness, calculated with the peak period $\mathrm{T}_{\mathrm{p}}$. Storm waves without depth limitation have often a wave steepness close to 0.04 . If waves break due to a shallow foreshore, like along the North Sea coast at Petten, the wave steepness reduces to 0.02 or even smaller. The range of wave steepness between 0.02 and 0.04 covers a large part of storm conditions along the Dutch coast.

From Flowdike I and II five tests were selected which cover the range of slopes 1:3 and 1:6 and wave steepnesses between 0.02 and 0.04 . One test was chosen to check the validity of the "scale test".

Front velocities can be obtained from the record of the wave run-up by taking a certain distance that the front has passed over the slope in a certain time. First of all the wave run-up signal has to be smooth, otherwise the velocities will show a large variation. The signal of test 456 has been smoothed by a 4 points moving average and becomes then quite smooth, see Figure 4. 


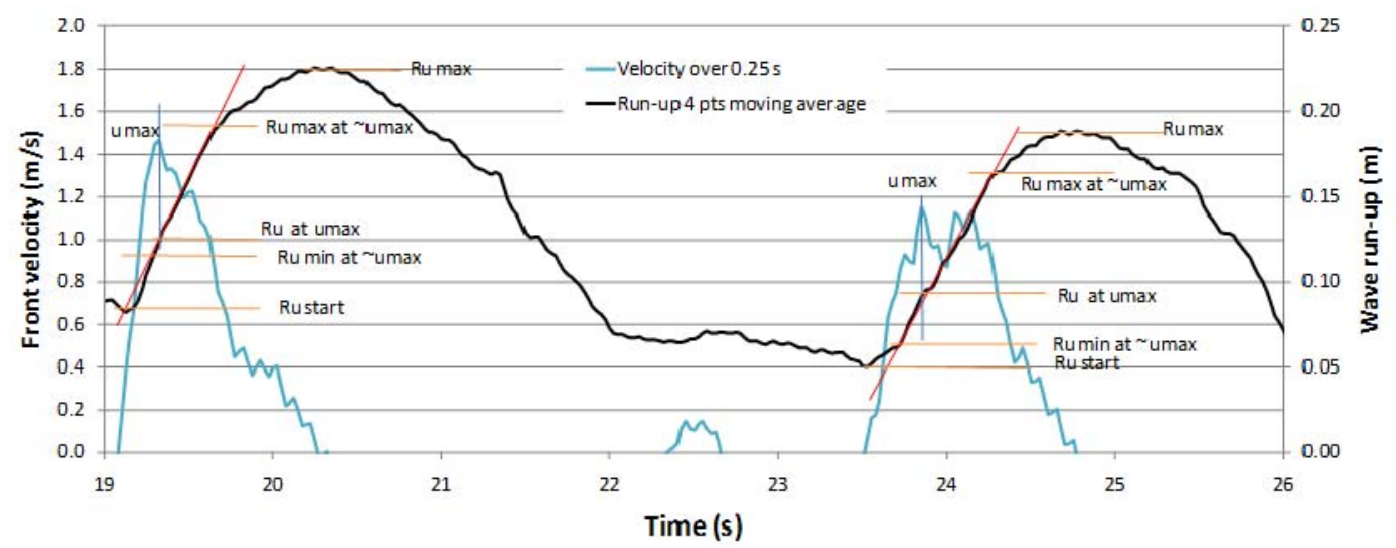

Figure 4. Record of two up-rushing waves with derived velocity from this record. Definition of five distinct run-up levels.

The prediction method for strength of grass covers at the crest and landward side of a dike (the cumulative overload method) depends on velocities exceeding a certain critical velocity. Only fairly large velocities contribute to initial or ongoing damage of the grass cover. It is for this reason that analysis of the front velocities was focused on the large velocities only, say the largest $10-20 \%$ of the velocities.

The maximum velocities were taken from this largest part. The run-up signal, however, gives also the location where this maximum velocity was found, as well as the maximum run-up level for that specific wave. The location of the maximum velocity has some variation, as time averaging was used.. Certainly when the run-down suddenly changes into run-up, it takes some time before the maximum velocity is calculated as a maximum. The real location for the maximum velocities, therefore, may be a little lower on the slope than calculated.

Maximum velocities, the location of this velocity on the slope and the maximum wave run-up of that specific wave were found by data processing. A closer inspection of Figures 4 shows that often the first part of the wave run-up signal is almost straight and the front velocity slows down quickly only close to the maximum run-up level. The velocity records in Figure 4 show a certain duration where the velocity is quite close to the maximum velocity (which is always a little peaked), say within about $20 \%$ of the peak value. For this reason the combined record of wave run-up and front velocity was judged by eye and three other locations were established from the data. In total the following locations where derived, see also Figure 4.

1. $\mathrm{Ru}_{\text {start }}$ : the location where the run-down changes into run-up

2. $\mathrm{Ru}_{\text {min at } \sim \text { max }}$ : the lowest location where the velocity is within about $20 \%$ of its maximum velocity

3. $\mathrm{Ru}_{\text {at umax }}$ : the location where $\mathrm{u}_{\max }$ has been calculated (data processing)

4. $\mathrm{Ru}_{\max }$ at $\sim$ max : the highest location where the velocity is within about $20 \%$ of its maximum velocity

5. $\mathrm{Ru}_{\max }$ : the maximum run-up level (data processing)

All these levels were established for the largest run-up levels and they have been compared in Figure 5. The 80 largest analyzed waves are given in the graph in ascending order with respect to the maximum run-up level. Figure 5 gives test 456 again on a 1:6 slope for a steepness of sop $=0.02$. The maximum run-up level covers the range from $0.18-0.35 \mathrm{~m}$. The $2 \%$-run-up level is given too, which makes it easy to find the waves that exceeded this level. The purple and dark red lines give the upper and lower boundaries where the velocity is large and close to the maximum velocity. A number of conclusions can be drawn from the graph.

There is not much difference between where the run-up starts and the minimum run-up level where the velocity is close to the maximum velocity: the two lines on the lower part of the graph are almost identical. These two lines also show that run-up does often start at a higher point than the still water level: the up-rushing wave reaches the down-rush of the previous wave before the run-down has reached the still water level (certainly at a 1:6 slope).

The other line for the upper boundary, where the velocity is still close to the maximum velocity, is always quite close to the maximum run-up level. This leads to the conclusion that a large velocity, close to the maximum velocity, is present from the start of run-up to a high level close to the maximum run-up. The maximum run-up in average is found closer to the lower boundary than the upper boundary. 


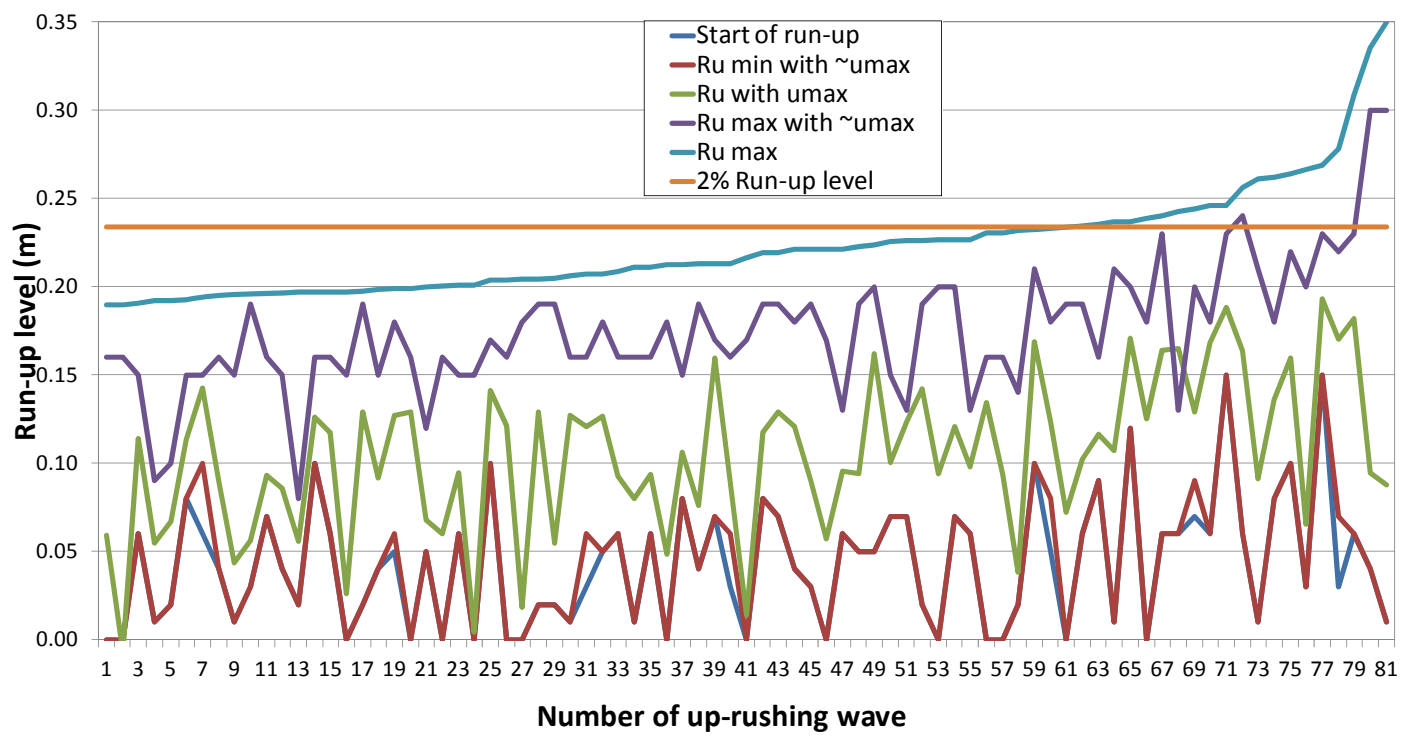

Figure 5. Various run-up levels in ascending order. Test 456, slope 1:6.

The total analysis has been described by Van der Meer (2011). Based on this analysis the following conclusion on the location of maximum or large velocities in the run-up of waves on the seaward slope of a smooth dike can be drawn, which is also shown graphically in Figure 6.

In average the run-up starts at a level of $15 \%$ of the maximum run-up level, with a velocity close to the maximum velocity and this velocity is more or less constant until a level of $75 \%$ of the maximum run-up level. The real maximum velocity in average is reached between $30 \%-40 \%$ of the maximum run-up level.

Figure 6 also shows that a square root function as assumed in Eq. 1 is not a correct assumption. The process of a breaking and impacting wave on the slope has influence on the run-up, it gives a kind of acceleration to the up-rushing water.

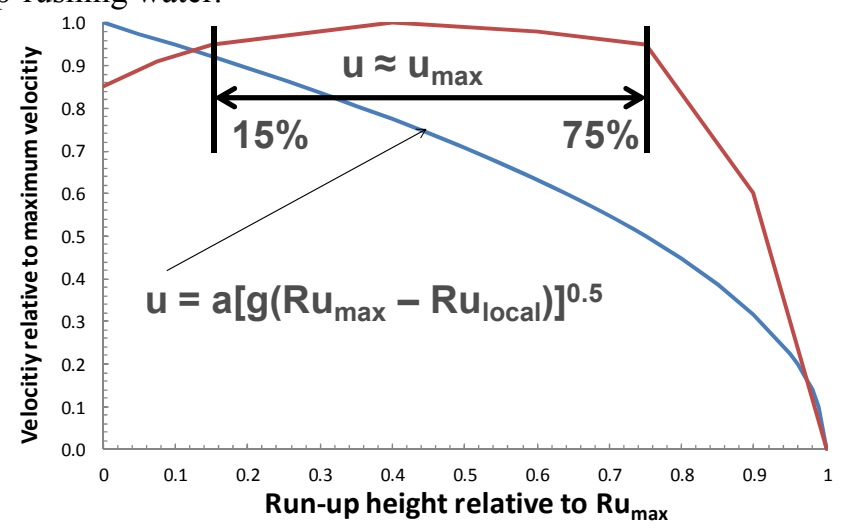

Figure 6. General trend of velocity over the slope during up-rush, compared to theory.

Further analysis showed that there is a clear trend between the maximum velocity in each uprushing wave and the (maximum) run-up level itself, although there is considerable scatter. Figure 7 shows the final overall figure (detailed analysis in Van der Meer (2011)), where velocity and maximum run-up level of each wave were made dimensionless. Note that only the largest velocities have been analysed and that the lower left corner of the graph in reality has a lot of data, but less significant with respect to effect on a grassed slope.

The aspect of the large scatter has not been described in earlier research. There is a similarity with the distribution of wave heights and wave periods in a sea state. There are small individual wave heights with small wave periods, but also with larger periods. There is a trend between individual wave heights and wave periods, but not a direct relationship other than that wave height and wave length may be Rayleigh distributed, but not with much correlation. And that seems similar for maximum velocities and the location on the slope where this velocity occurs, or the relative run-up (as in Figure 7). 


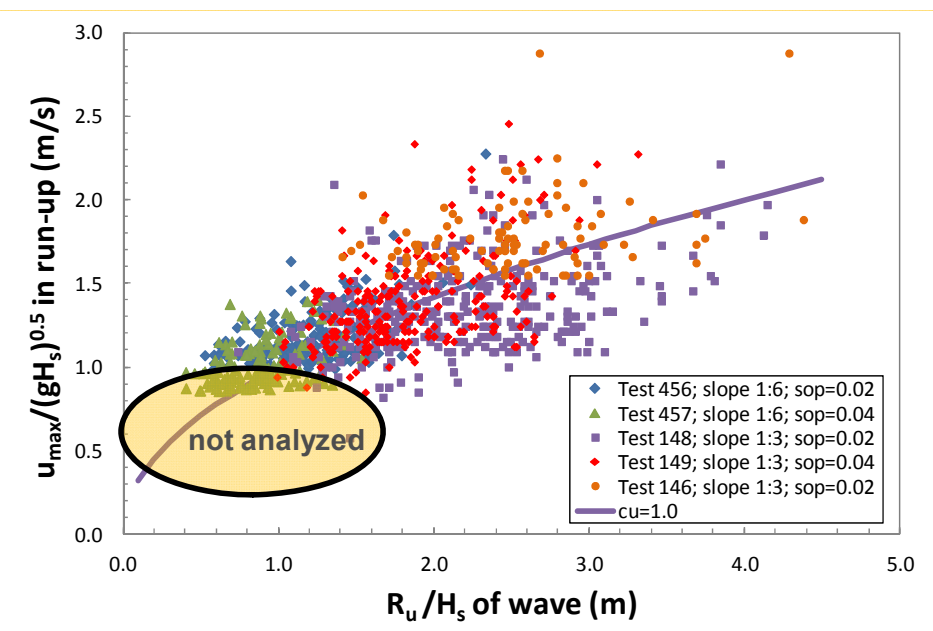

Figure 7. Relative maximum velocity versus relative run-up on the slope; all tests.

The trend and conclusion in Figure 6 explains for a part why the relationship between the maximum velocity and the maximum run-up in Figure 7 gives a lot of scatter. A velocity close to the maximum velocity is present over a large part of the slope and the actual location of the maximum velocity may be more or less "by accident".

The trend given in Figure 7 can be described by:

$$
\mathrm{u}_{\max } /\left(\mathrm{gH}_{\mathrm{s}}\right)^{0.5}=\mathrm{c}_{\mathrm{u}}\left(\mathrm{Ru}_{\max } / \mathrm{H}_{\mathrm{s}}\right)^{0.5}
$$

with $\mathrm{c}_{\mathrm{u}}$ as stochastic variable with $\mu\left(\mathrm{c}_{\mathrm{u}}\right)=1.0$ and a normal distribution with $\mathrm{V}=0.25$.

\section{SIMULATION OF WAVE RUN-UP}

\section{Set-up of the test}

Wave run-up tests on the seaward side of a dike have been performed at Tholen, in the Netherlands, in 2011. Also hydraulic measurements have been performed on flow velocity and thickness in the run-up as well as the run-down phase. The down slope is a conventional placed block revetment on a slope 1:4, then a 1:20 berm is present at a height of $4.2 \mathrm{~m}+\mathrm{NAP}$ (NAP = Chart Datum). The lower part of the berm consists of an asphalt cycle path also used as maintenance road, the upper part is a grassed slope. The total width of the berm is about $4 \mathrm{~m}$. Finally, an upper slope is present with a slope of 1:3 terminating at a height of $6.8 \mathrm{~m}+\mathrm{NAP}$.

The Wave Overtopping Simulator was used to create up-rushing waves on the berm and upper part of the slope and the outflow point of the simulator was placed just on the asphalt berm with the actual simulator on the down slope. Figure 8 shows a set-up of the testing. Wave run-up was simulated over the berm (asphalt and grassed slope) and the upper grassed slope. With released volumes larger than $4000 \mathrm{l} / \mathrm{m}$ the up-rushing water reached the crest and overtopping was created.

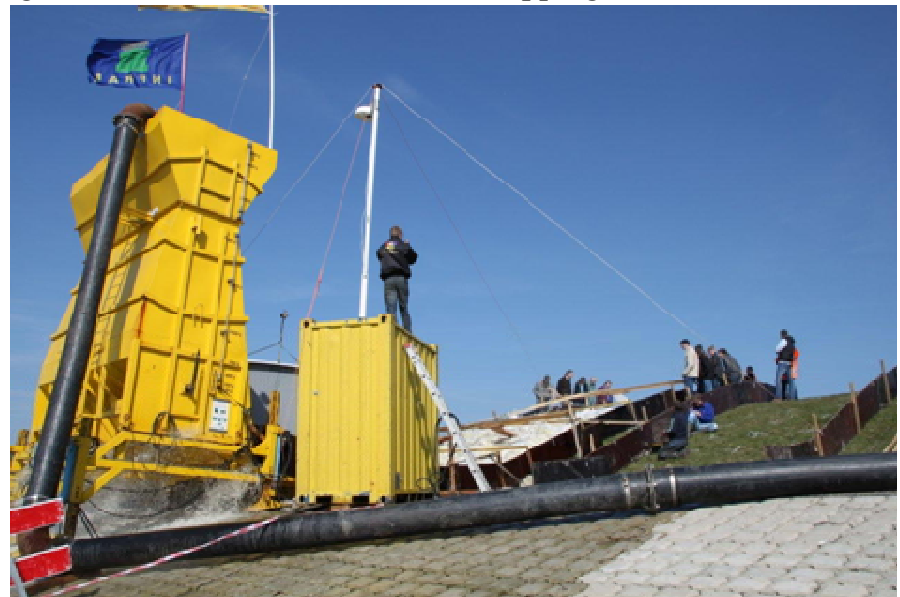

Figure 8. Set-up of the pilot wave run-up test at Tholen, using the existing Wave Overtopping Simulator. 
In order to be able to perform correct wave run-up tests the relationship between released volume and run-up height or level should be established. This was first performed at the steep inner slope (slope 1:2.4) at the Tholen dike and the found relationship was used to create the steering files for the run-up test. Figure 9 shows the set-up during this calibration of run-up levels, where the simulator outflow was directly placed against the slope (no horizontal transition). When the simulator was present on the seaward side for the testing on run-up similar calibration tests were performed to establish the relationship between released volume and run-up level, but now for the almost horizontal berm and more gentle upper slope.

The results of both calibrations are given in Figure 10. The largest run-up level on the steep 1:2.4 slope was about $3.5 \mathrm{~m}$. The calibration on the 1:3 seaward slope terminates for $4000 \mathrm{l} / \mathrm{m}$ and larger as the crest is reached by the up-rushing wave and overtopping started. With similar released volumes the run-up was a little larger on the 1:3 slope with the berm in front. The actual slope was a little rounded, and the calibration for this slope is given in Figure 10 as well.
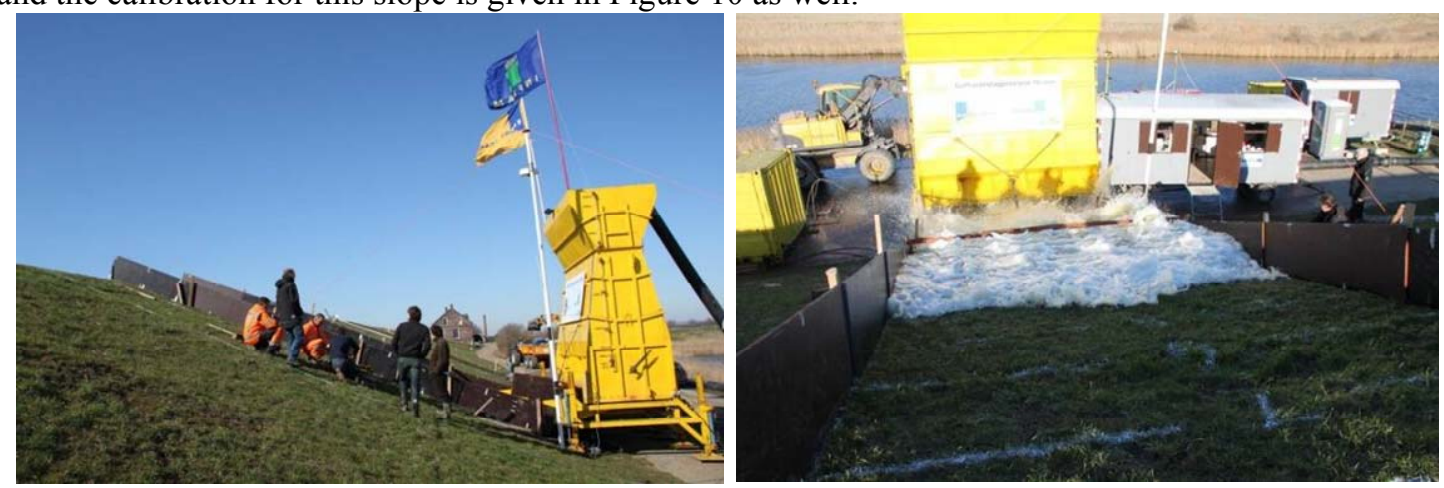

Figure 9. Calibration of run-up levels on a steep slope 1:2.4.

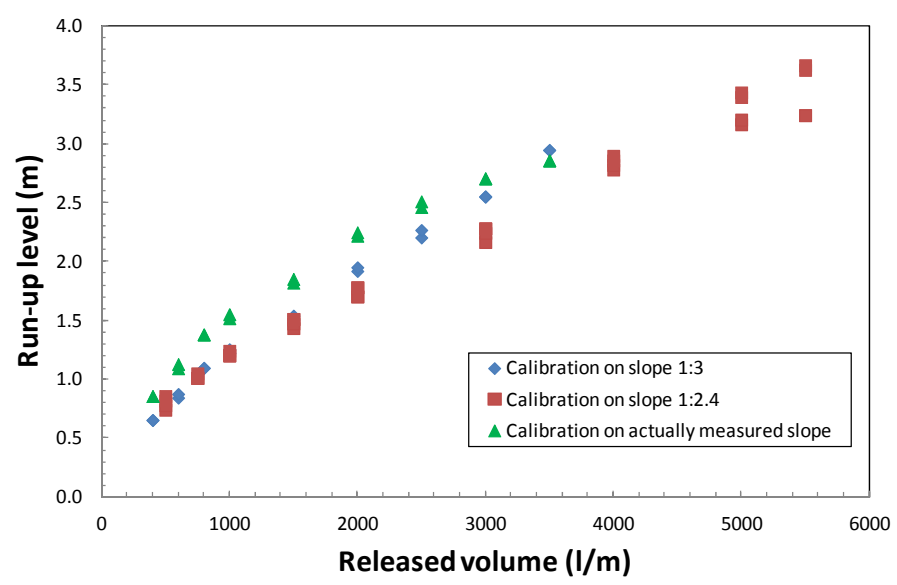

Figure 10. Calibration results on run-up levels for different slopes.

\section{Definition and simulation of tests}

On the seaward side waves break and then run up and down along the upper part of the seaward slope. The run-up process is more or less similar to the overtopping process, although in this case the front velocity of the up-rushing wave decreases with run-up height, where for the wave overtopping the velocity is more or less constant along the whole slope. It has been observed that it is the front of the wave (overtopping or up-rushing) which causes damage to grass slopes. This implies that run-down does not give significant loading to the grass, as run-down does not have a wave front. For the time being wave run-down is not considered as a main load, only the wave run-up.

In order to look at a specific case a wave condition (wave height, wave period) has to be chosen for a certain geometry of the dike, together with a given water level. Or a location on the dike slope could be defined to where the $2 \%$-run-up value should come, giving then the associated water level. With the fixed water level the distribution of run-up levels on the slope is known. The vertical distance from the still water level to a considered location on the slope is described by $z_{1}$. 
In the previous sections it has been concluded that the maximum front velocity in an up-rushing wave is almost constant in the area starting $15 \%$ from the water level to $75 \%$ of the actual run-up level. Beyond this level the front velocity will quickly reduce to zero at the maximum run-up level for that specific wave (Figure 6). The main area to be considered, therefore, is the area where the maximum velocity is more or less constant. Assuming that $z_{1}$ is always higher than the minimum level of $15 \%$ of the maximum run-up level, then all run-up levels higher than $\mathrm{z}_{1} / 0.75$ will contribute to a front velocity $\mathrm{u}$ which should be considered for the method of cumulative overload. In case the location $\mathrm{z}_{1}$ would be very close to the water level it is proposed to take $\mathrm{z}_{1}$ at $0.15 \mathrm{Ru}_{2} \%$.

The $2 \%$-wave run-up level depends on wave conditions and dike geometry. Formulae and programs are available (EurOtop (2007)) to calculate this 2\%-run-up level for all kinds of structures. The wave run-up distribution has often been observed as a Rayleigh distribution. The relationship between maximum velocity and run-up level is given by Eq. 3. Above procedure gives the distribution of maximum front velocities along the slope and also for a fixed point $\mathrm{z}_{1}$.

As example the tested situation at Tholen will be used. The cross-section consists of a 1:4 down slope with a block revetment, a berm at $+4.2 \mathrm{~m}$ NAP (NAP $=$ chart datum) of asphalt and a grassed 1:3 upper slope with a crest at $+6.8 \mathrm{~m}$ NAP. Although the berm in reality had a slope of $1: 20$, for this example a horizontal berm is assumed. The transition from protected to unprotected (= grass) is at this level of +4.2 m NAP.

For test conditions a wave height is assumed of $\mathrm{H}_{\mathrm{s}}=2 \mathrm{~m}$ and $\mathrm{T}_{\mathrm{p}}=5.7 \mathrm{~s}$ (wave steepness $\mathrm{s}_{\mathrm{op}}=0.04$ ), which is similar as for previous tests with the Wave Overtopping Simulator. For simplicity a straight 1:4 slope is assumed and not the bermed section of Tholen. This gives a 2\%-run-up level of $\mathrm{Ru}_{2 \%}=4.0 \mathrm{~m}$. The storm duration is taken at 6 hours, giving 4547 up-rushing waves (with $\mathrm{T}_{\mathrm{m}}=4.75$ s). A Rayleigh distribution is assumed for the run-up levels. This distribution is given with respect to the still water level.

The distribution of run-up levels with respect to the slope depends then on the still water level applied. In this example the still water level is assumed at $+1.8 \mathrm{~m} \mathrm{NAP}$, this is $2.4 \mathrm{~m}$ below the berm. Figure 11 shows the run-up levels on a Rayleigh scale, which gives a straight line in the graph. It also shows that only $25 \%$ of the up-rushing waves reach the berm.

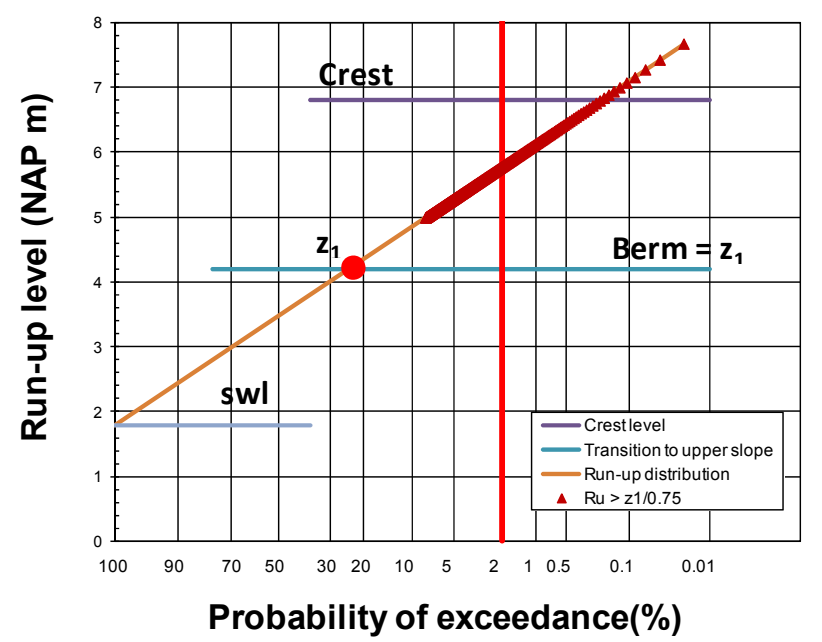

Figure 11. Assumed wave run-up distribution on the cross-section at Tholen.

The figure gives the still water level, the berm level, the crest level and the point $z_{1}$ at the berm level. Also the $2 \%$ level is given by a vertical line. The solid line gives the full distribution of run-up levels. Only run-up levels higher than $z_{1} / 0.75$, where $z_{1}$ is the berm level at $+4.2 \mathrm{~m}$ NAP, will be taken into account. These are run-up levels larger than $2.4 / 0.75+1.8=+5.0 \mathrm{~m}$ NAP. Each run-up level is given by a triangle. In total about $8 \%$ of the up-rushing waves reach this level. In total 9 run-up levels will exceed the crest level of $+6.8 \mathrm{~m}$ NAP, giving wave overtopping over the crest.

The execution of the pilot test on run-up started with a low water level and this water level was increased after every six hours of storm duration. In total five storms (water levels) were simulated, where the test with the final and highest water level was stopped after four hours. The run-up levels on the slope for each test condition are given in Figure 12. The difference between water level and the 
berm was called $\mathrm{x}$, which here is indicated as $\mathrm{z}_{1}$. Values of $\mathrm{x}$ or $\mathrm{z}_{1}$ were respectively applied of $\mathrm{x}=\mathrm{z}_{1}=$ $4.5 ; 4.0 ; 3.2 ; 2.4$ and $1.6 \mathrm{~m}$. The actually simulated run-up levels are given by the triangle symbols and are sometimes different from the straight line.

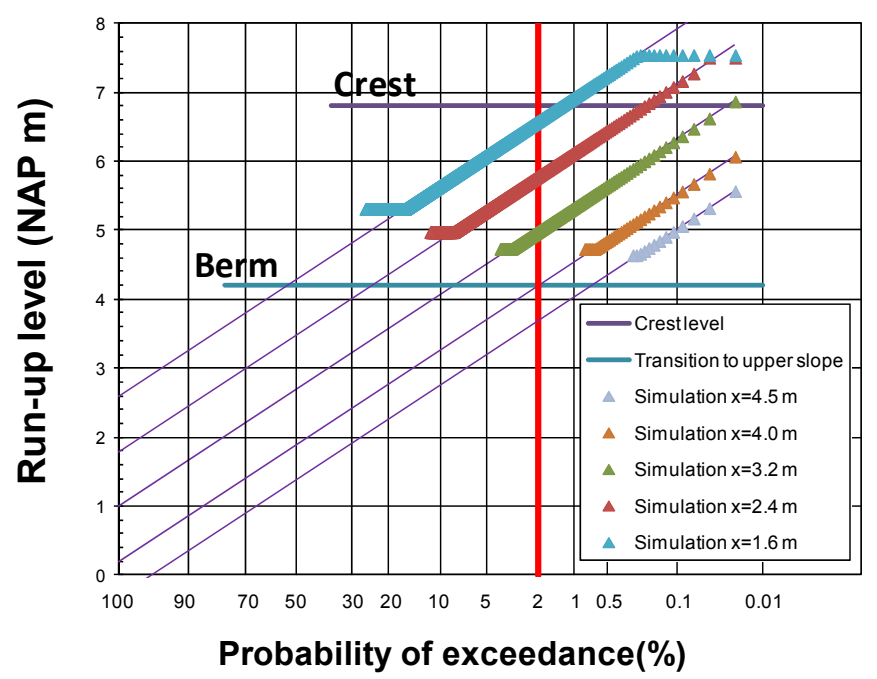

Figure 12. Actually simulated run-up levels at Tholen.

\section{Test results}

Only one pilot test has been performed, with five sub-tests as described above. The test results were as follows:

- Only small surface erosion was noticed for tests with $\mathrm{x}=\mathrm{z}_{1}=4.5 \mathrm{~m}$ and $4.0 \mathrm{~m}$.

- A first small erosion hole at the transition from berm to upper slope, about $7 \mathrm{~cm}$ deep, was noticed after 2 hours with $\mathrm{x}=\mathrm{z}_{1}=3.2 \mathrm{~m}$. After the full test there were three small erosion holes each about $7 \mathrm{~cm}$ deep. This damage is close to the criterion of "several open spots".

- Damage increased during the next tests. The test was stopped after 4 hours with $x=z_{1}=1.6 \mathrm{~m}$. A cliff had been formed at three holes at the transition from berm to upper slope with a height of about $0.5 \mathrm{~m}$. The upper slope had not yet failed, see Figure 13, but the test had to be terminated as problems with the side boards (large hydraulic loads) led to unwanted effects.

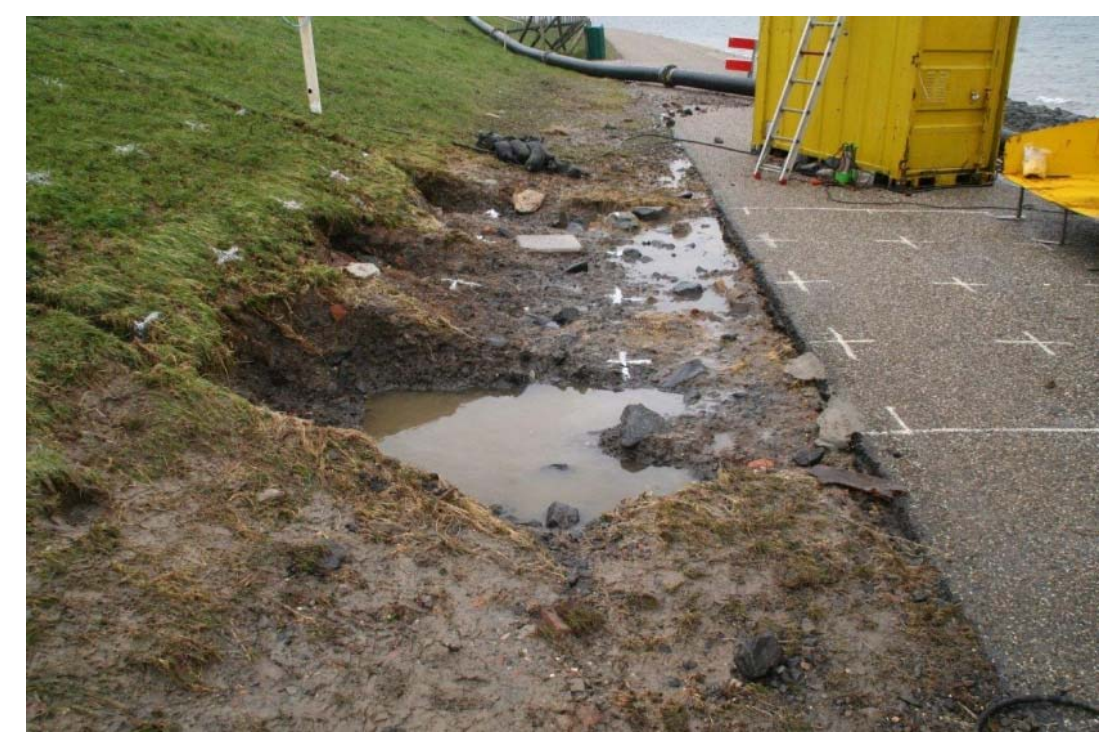

Figure 13. Final damage after the pilot run-up test. 


\section{HYDRAULIC MEASUREMENTS}

A session on hydraulic measurements was performed besides the actual pilot test. For the hydraulic measurements two surfboards have been used for measurement of flow thickness and eight paddle wheels for flow velocity (see Van der Meer et al. (2010) for a detailed description). One surfboard was placed on the crest and could only measure overtopping waves (volumes of $40001 / \mathrm{m}$ and larger). After run-up the water runs down the slope what may hit the surfboard from the wrong side and damage it. For this reason a modified surfboard was developed, which is more rounded than the existing ones. Also a down rushing wave will then tilt the surfboard to float on the water surface. Figure 14 shows the set-up of the hydraulic measurements, including this modified surfboard.
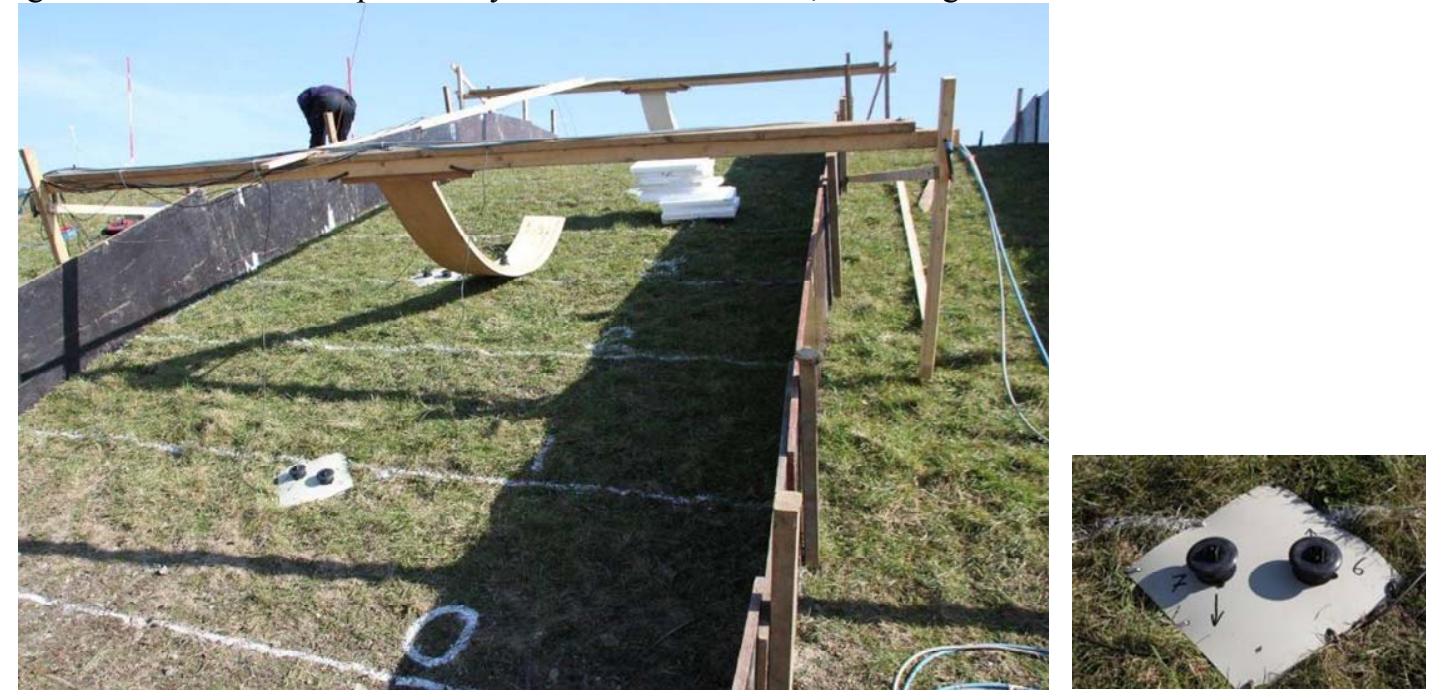

Figure 14. Set-up of hydraulic measurements on run-up with modified surfboard and velocity measurements up and down the slope.

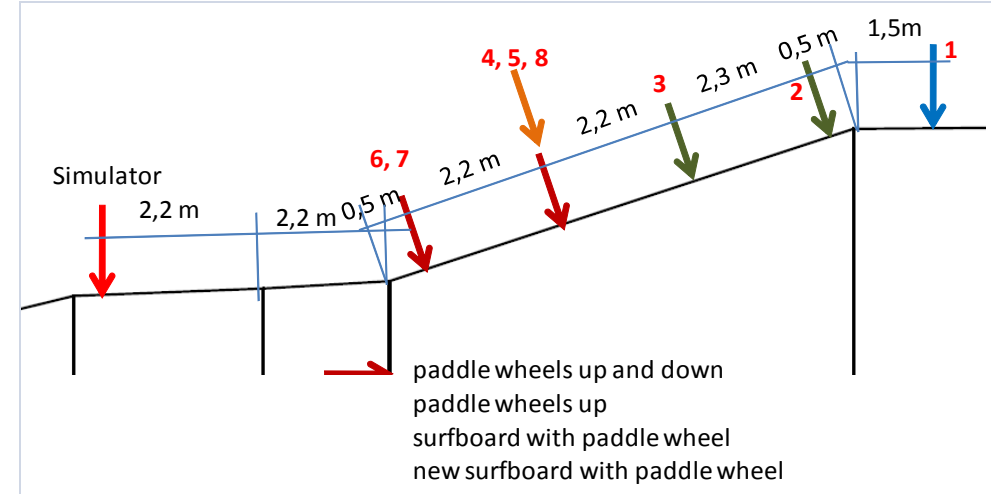

\begin{tabular}{|l|l|}
\hline \multicolumn{2}{|l|}{ Instrument Location } \\
\hline New SB1 & $1.5 \mathrm{~m}$ on crest \\
\hline PW1 & In SB1 \\
\hline PW2 & $0.5 \mathrm{~m}$ from crest \\
\hline PW3 & $2.7 \mathrm{~m}$ from crest \\
\hline SB5 & $4.9 \mathrm{~m}$ from crest \\
\hline PW8 & in SB5 \\
\hline PW4 & $4.9 \mathrm{~m}$ from crest \\
\hline PW5 down & $4.9 \mathrm{~m}$ from crest \\
\hline PW6 & $7.1 \mathrm{~m}$ from crest \\
\hline PW7 down & $7.1 \mathrm{~m}$ from crest \\
\hline & \\
\hline $7.1 \mathrm{~m}=0.90 \mathrm{~m}$ from berm/slope \\
\hline
\end{tabular}

Figure 15. Locations of surfboards and paddle wheels on the slope.

Paddle wheels were mounted in both surfboards. Another six paddle wheels were mounted in a plate on the ground surface, but measured the velocity $3 \mathrm{~cm}$ above this level (just outside the boundary layer). Paddle wheels can turn around in two directions, but only one direction is the correct one. For this reason two paddle wheels have to be used for measuring run-up as well as run-down. On two locations on the slope two paddle wheels were mounted next to each other, but measuring opposite directions, see also Figure 14. The other paddle wheels were placed in between the others. The precise locations of surfboards and paddle wheels is shown in Figure 15.

Figure 16 shows an overall view of all paddle wheels that measured run-up in the correct direction. Paddle wheels higher up the slope get only run-up if the released volume is large enough and consequently the run-up comes high enough. Comparison of PW6 with PW4 and PW8 shows that they all give similar velocities, although PW 4 and PW8 are located higher on the slope. This agrees well with the analysis of real wave run-up, where it was concluded that the maximum velocity, or close to it, is present over a large part of the run-up area. Only in the last $15 \%$ of the run-up the velocity slows 
down. Figure 16 validates this more or less, where flow velocities of 4000 1/m and more (which reach all instruments) are given against the location on the slope.

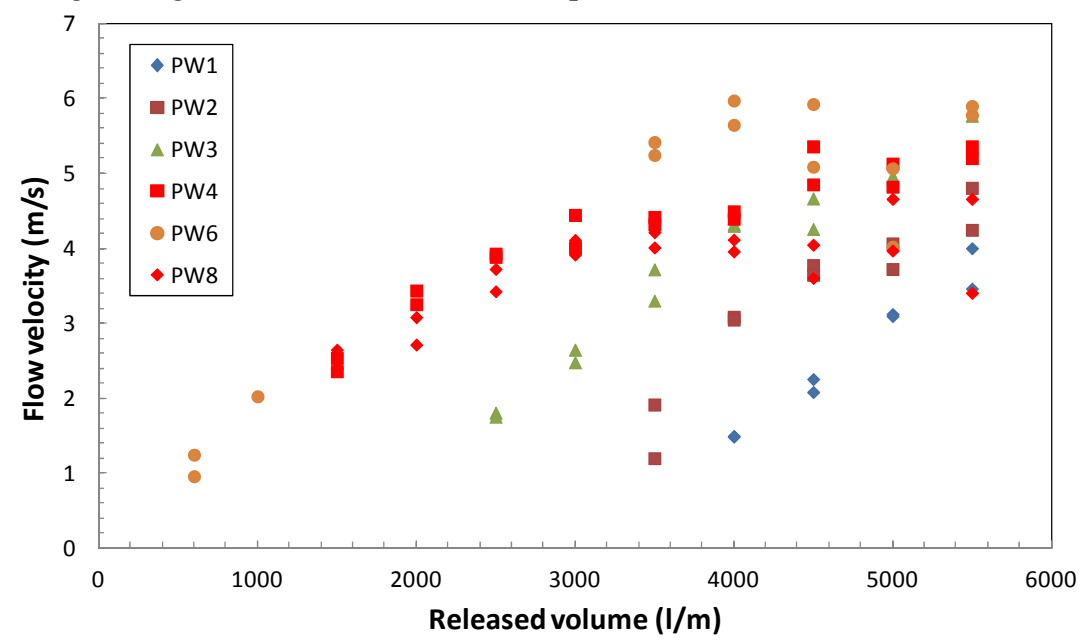

Figure 16. Measured run-up maxima at various locations.

Flow thicknesses have been measured by only two surf boards, one on the lower part of the slope (SB5) and one on the crest (SB1). The latter measures only flow thickness if the run-up exceeded the crest height, which was for released volumes of $4000 \mathrm{l} / \mathrm{m}$ and more. Figure 17 shows the increasing flow thickness with increasing released volume. Even on the crest a flow thickness of $0.15 \mathrm{~m}$ was reached for 5,500 1/m (with a flow velocity of $3.7 \mathrm{~m} / \mathrm{s}$ ).

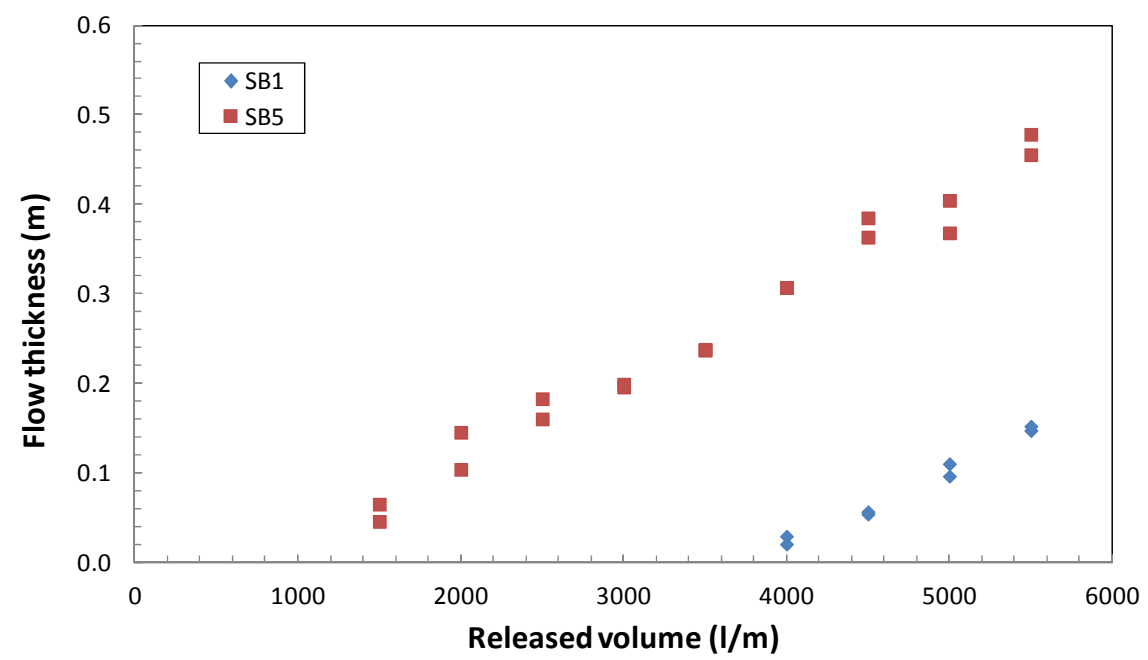

Figure 17. Measured flow thicknesses during run-up at two locations.

\section{IMPROVEMENT OF WAVE RUN-UP SIMULATION}

The pilot test gave valuable insight in how such a test can be improved to simulate the wave runup process as realistically as possible. The following conclusions can be made:

- All the released water rushing up the slope comes back by run-down. This water cannot be released immediately down the slope as the simulator was placed only $0.2 \mathrm{~m}$ above the berm. Water concentrates in front of the simulator and gives large forces to the side walls. Actually, the test had to be terminated as the stability of the side walls became insufficient as well as leaking underneath the side walls led to unwanted side effects (erosion). A necessary improvement is to stabilize the side walls close to the simulator and to seal the side walls in this area.

- The wave overtopping simulator was designed to give large overtopping volumes with the correct velocity and flow thickness at the crest of the dike. This led to the shape of the present simulator. By using it for run-up simulation it appeared that the wave run-up along the slope is quite fast (within a few seconds) and starts to run down when the remaining water in the simulator is still released. This gives a "bump" of water on the slope, see Figure 18. Actually there is too much 
water in the simulator, in combination with a limited valve opening. The main improvement would be to change the shape of the simulator to a much slender one, preferably with the same size as the valve opening.

- Each released volume gives only one run-up level and one maximum velocity at a certain location. Analysis of wave run-up velocities (Figure 7) shows that for more or less the same run-up level there might be a range of maximum velocities. This can only be simulated if the opening of the valve can be steered to a prescribed opening. A fully open valve will then give the largest velocities, where a partly open valve will reduce them. This system of steering has already been developed on the Wave Overtopping Simulator in the USA and should be implemented on an improved Wave Run-up Simulator.

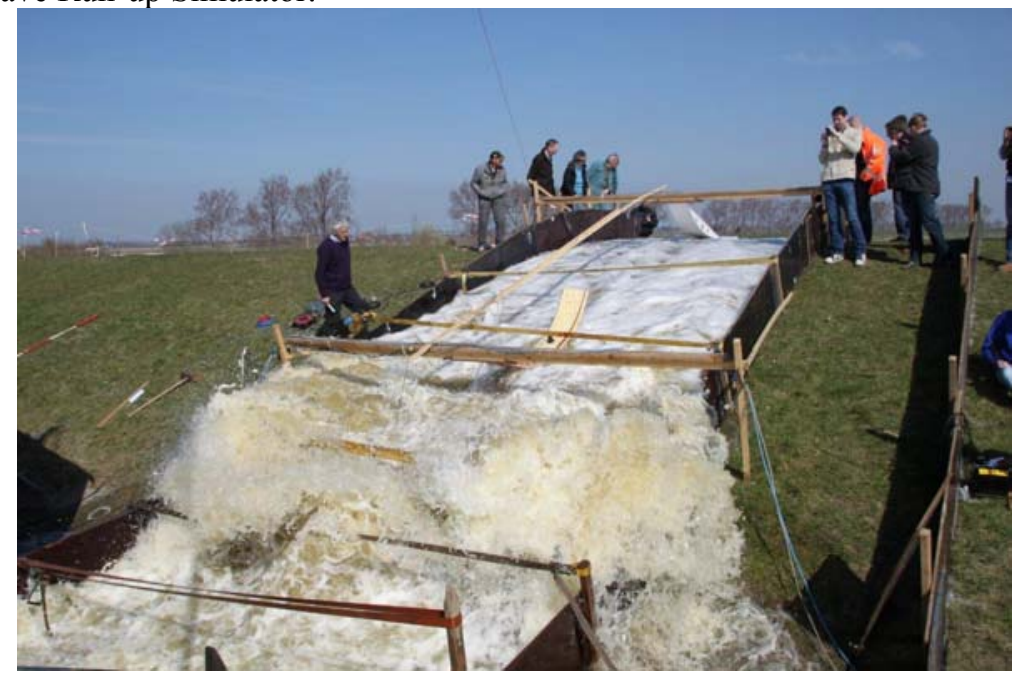

Figure 18. Run-down meeting up-rushing water during the wave run-up simulation process.

\section{CONCLUSIONS}

In order to simulate a process this process has to be described in depth. The conventional design parameter $\mathrm{Ru}_{2} \%$ is a starting point, but much more should be known on correlation of run-up levels and associated velocities all along the slope. A detailed analysis is given in Van der Meer (2011) and this analysis showed that there is a large scatter in the correlation between run-up level and maximum velocity. This scatter is similar as the scatter between individual wave heights and periods in a storm. In contrast to the theory (Eq. 3), the evolution of the front velocity of an up-rushing shows a maximum at about $40 \%$ of the maximum run-up level and a velocity close the maximum velocity is present between $15 \%$ and $75 \%$ of the maximum run-up level. The reason is that the breaking wave gives an acceleration to the up-rushing wave tongue.

The pilot test on wave run-up simulation gave a lot of insight in what would be possible with an improved Simulator. Some possible improvements have been described in the previous section. The performance of the tests by five sub-tests, with increasing water level and increasing number of run-up levels on the upper slope, gave damage at the transition from berm to upper slope. This type of damage could be expected and is similar to overtopping damage at the toe of the dike, where also a transition is present, but now from a slope to a horizontal part.

The hydraulic measurements were successful, showing the evolution of maximum velocity and flow thickness over the upper slope. Even overtopping waves were simulated at the crest with a velocity

$4 \mathrm{~m} / \mathrm{s}$ and a flow thickness of $0.15 \mathrm{~m}$.

\section{REFERENCES}

Akkerman, G.J., P. Bernardini, J.W. van der Meer, H. Verheij and A. van Hoven. 2007. Field tests on sea defences subject to wave overtopping. Proc. Coastal Structures, Venice, Italy.

Bosman, G, J.W. van der Meer, G. Hoffmans, H. Schüttrumpf and H.J. Verhagen. 2008. Individual overtopping events at dikes. ASCE, proc. ICCE 2008, Hamburg, Germany, p. 2944-2956.

EurOtop Manual. 2007. Wave Overtopping of Sea Defences and Related Structures - Assessment Manual. UK: N.W.H. Allsop, T. Pullen, T. Bruce. NL: J.W. van der Meer. DE: H. Schüttrumpf, A. Kortenhaus. www.overtopping-manual.com. 
Hoffmans, G., G.J. Akkerman, H. Verheij, A. van Hoven and J.W. van der Meer. 2008. The erodibility of grassed inner dike slopes against wave overtopping. ASCE, Proc. ICCE 2008, Hamburg, 32243236.

Le Hai Trung, J.W. van der Meer, G.J. Schiereck, Vu Minh Cath and G. van der Meer. 2010. Wave Overtopping Simulator Tests in Vietnam. ASCE, Proc. ICCE 2010, Shanghai.

Lorke, S., A. Brüning, J.W. van der Meer, H. Schüttrumpf, A. Bornschein, S. Gilli, R. Pohl, M. Spano, J. Riha, S. Werk and F. Schlütter. 2010. On the effect of current on wave run-up and wave overtopping. ASCE, Proc. ICCE 2010, Shanghai.

Schüttrumpf, H. and M.R.A. van Gent, 2003. Wave overtopping at seadikes. ASCE, proc. Coastal Structures 2003, p. 431-443.

Schüttrumpf, H.F.R. 2001. Wellenüberlaufströmung bei See-deichen, Ph.D.-thesis, Technical University Braunschweig.

Steendam, G.J., W. de Vries, J.W. van der Meer, A. van Hoven, G. de Raat and J.Y. Frissel. 2008. Influence of management and maintenance on erosive impact of wave overtopping on grass covered slopes of dikes; Tests. Proc. FloodRisk, Oxford, UK. Flood Risk Management: Research and Practice - Samuels et al. (eds.) ISBN 978-0-415-48507-4; pp 523-533.

Steendam, G.J., J.W. van der Meer, B. Hardeman and A. van Hoven. 2010. Destructive wave overtopping tests on grass covered landward slopes of dikes and transitions to berms. ASCE, Proc. ICCE 2010, Shanghai.

Steendam, G.J., P. Peeters., J.W. van der Meer, K. Van Doorslaer, and K. Trouw. 2011. Destructive wave overtopping tests on Flemish dikes. ASCE, Proc. Coastal Structures 2011, Yokohama, Japan.

Thornton, C., J.W. van der Meer and S.A. Hughes. 2011. Testing levee slope resiliency at the new Colorado State University Wave Overtopping Test Facility. Proc. Coastal Structures 2011, Japan.

Van der Meer, J.W., P. Bernardini, W. Snijders and H.J. Regeling. 2006. The wave overtopping simulator. ASCE, ICCE 2006, San Diego, pp. 4654 - 4666.

Van der Meer, J.W., P. Bernardini, G.J. Steendam, G.J. Akkerman and G.J.C.M. Hoffmans. 2007. The wave overtopping simulator in action. Proc. Coastal Structures, Venice, Italy.

Van der Meer, J.W., G.J. Steendam, G. de Raat and P. Bernardini. 2008. Further developments on the wave overtopping simulator. ASCE, Proc. ICCE 2008, Hamburg, 2957-2969.

Van der Meer, J.W., R. Schrijver, B. Hardeman, A. van Hoven, H. Verheij and G.J. Steendam. 2009. Guidance on erosion resistance of inner slopes of dikes from three years of testing with the Wave Overtopping Simulator. Proc. ICE, Coasts, Marine Structures and Breakwaters 2009, Edinburgh, UK.

Van der Meer, J.W., B. Hardeman, G.J. Steendam, H. Schttrumpf and H. Verheij. 2010. Flow depths and velocities at crest and inner slope of a dike, in theory and with the Wave Overtopping Simulator. ASCE, Proc. ICCE 2010, Shanghai.

Van der Meer, J.W., C. Thornton and S. Hughes. 2011. Design and operation of the US Wave Overtopping Simulator. ASCE, Proc. Coastal Structures 2011, Yokohama, Japan.

Van der Meer, J.W. 2011. The Wave Run-up Simulator. Idea, necessity, theoretical background and design. Van der Meer Consulting Report vdm11355.

Van Gent, M.R.A. 2002. Low-exceedance wave overtopping events. Delft Hydraulics project id. DC030202/H3803. 